\title{
Crises na educação, representação e formação de professor: uma contribuição do pensamento complexo na obra de Morin
}

\author{
Crisis in education, representation and teacher training: \\ a contribution of complex thinking in Morin's work \\ Crisis en la educación, representación y formación docente: \\ una contribución del pensamiento complejo en el trabajo de Morin
}

MARIA DE FÁTIMA DE ANDRADE FERREIRA

Orcid Id: http://orcid.org/0000-0003-4094-6741

Universidade Estadual do Sudoeste da Bahia

CINTHIA MARIA SEIBERT SANTOS

Orcid Id: http://orcid.org/0000-0002-9286-8485

Centro Universitário Mauricio de Nassau

\begin{abstract}
Resumen: Este artigo é uma reflexão sobre crises na educação, representação e formação de professor, buscando destacar razões do mal-estar em tempos de crises contemporâneas e, de que modo as políticas públicas educacionais são implementadas nessa direção. Os desafios à formação docente são diversos, merecem tratamento rigoroso e devem fazer parte de discussões que nos retire da banalidade, autoritarismo, "achismos", com que o conhecimento é tratado pela escola e setores responsáveis pela educação como direitos para todos brasileiros.
\end{abstract}

Palabras-clave: Teoria da Complexidade; Teoria das Representações Sociais; Imaginário Social. Formação docente; Direitos à educação

Resumo: This article is a discussion about crises in education, representation, and teacher education, searching to show reasons for unrest in times of contemporary crises and how public and educational policies are implemented in this direction. The challenges of teacher training are diverse, they deal rigorously and must be part of discussions that retire from banality, authoritarianism, "guesswork", with which knowledge is treated by the school and responsible sectors for education as rights for all Brazilians.

Palavras-chave: Complexity Theory; Theory of Social Representations; Social Imaginary; Teacher training; Rights to education.

\begin{abstract}
Este articulo es una discusión sobre las crisis en la educación, representación y educación docente, buscando mostrar las razones de los disturbios en tiempos de crisis contemporáneas y cómo las políticas públicas y educativas se implementan en esta dirección. Los desafios de la formación del profesorado son diversos, se abordan rigurosamente y deben ser parte de las discusiones que se retiran de la banalidad, el autoritarismo, las "conjeturas", con el conocimiento por la escuela y los sectores responsables de la educación como derechos para todos los brasileños.
\end{abstract}

Keywords: Teoría de la complejidad; Teoría de las representaciones sociales; Imaginario social. Formación del profesorado; Derechos a la educación. 


\section{INTRODUÇÃO}

A sociedade brasileira contemporânea enfrenta questões políticas, sociais, educacionais, repletas de sinais confusos, imprevisíveis, e os processos históricosociais configuram-se por meio de avanços, permanências e retrocessos, em que novos problemas emergem a todo vapor e a pandemia de COVID-19 cruzou a linha, desafiou o mundo e surgem novas dificuldades. O ensino a distância como solução emergencial passa a ser um desafio à humanidade de modo geral e à educação de modo particular.

É um cenário que coloca conflitos, crises e desafios a serem superados para todos que desejam transformação social, no sentido da busca por solidariedade, respeito à diferença, diversidade, cidadania, dignidade humana. Crises e conflitos diversos têm causado sofrimento, dor, insegurança social às pessoas no mundo. Os diferentes indícios de vida insegura por múltiplos aspectos (sociais, econômicos, políticos, culturais) surgem de modo facetado.

Sobre a crise na educação brasileira, identificamos muitos motivos para dizer que a escola e o professor têm um papel importante no processo de construção do conhecimento, cidadania e melhoria do desempenho dos alunos. É urgente a provocação de mudanças de posturas, concepções de ensinar e aprender na escola; os sistemas de ensino e a responsabilidade na formulação de políticas públicas educacionais não podem ficar fora dessa provocação. De certa maneira, há muitas provocações, perspectivas, desafios sobre formação do professor para atender às emergências da educação remota em tempos de pandemia.

Porém, é preciso preparar-se para o inesperado e as barbáries de ideias que circundam a sociedade em tempos sombrios, um cenário contaminado pelo autoritarismo escancarado, produção de fake news, ataques ao Estado democrático de direito, escândalos envolvendo políticos, atos antidemocráticos financiados e disseminados no país, uma sociedade que experimenta a banalização do mal. Por isso mesmo que se descortinam desigualdades extremas, negação de direito a ter direitos, o vulnerável dos vulneráveis em diferentes espaços sociais, sem precedentes. Não para por aí. A escola e o professor encontram barreiras e não devem perder de vista a responsabilidade que é dada para eles, quando não se encontram preparados para atender aos desafios e obrigações, que lhes são colocados diante da falta de recursos tecnológicos para o ensino remoto, falta de acesso às condições necessárias para atender às demandas educacionais emergentes e enfrentar as crises. A população negra e pobre está muito distante das tecnologias digitais e encontra-se impedida de participar da educação à distância. 
Com as dificuldades de acesso a instrumentos pedagógicos para acompanhar a educação e ensino à distância dentro de casa, as desigualdades educacionais tornam-se um grande desafio, ficam escancaradas, tornam-se visíveis. A miséria material "de uns está diretamente relacionada à miséria ética, afetiva e espiritual de outros" (VIVERET, 2013, p. 40). Mas também, é uma vida de aprendizagens, o homem é tecido por uma teia de cultura, "amarrado a teias de significados que ele mesmo teceu” (GEERTZ, 2001). Sem dúvida, é preciso enfrentar o autoritarismo que está muito presente na ideia de bom senso e o pior é que sabemos muito bem disso.

$\mathrm{Na}$ era de barbáries e crises vividas na educação, as ambiguidades sobre o tempo de pandemia apresentam-se atravessadas pelo autoritarismo desenfreado e outras crises que atingem a família brasileira, trabalho, emprego etc. Tratam-se de crises na política, economia, fragilidades das estruturas da saúde, catástrofes naturais, violências, racismo, machismo, homofobia e seus efeitos que marcam o começo de um novo tempo. As tomadas de decisão e acesso à participação na educação dependem não só das intenções das pessoas envolvidas, mas das condições próprias do meio em que se desenrolam. Educação e saúde são direitos humanos e precisam caminhar em confluências e, cada uma, com capacidade de se auto-organizar e estabelecer relações com o "tu", transformando-se continuamente.

As crises agravam incertezas. De que crises falamos? São múltiplas, diversas, complexas e se entrelaçam. As pessoas se encontram numa sociedade de insegurança, medo, barbárie, mas buscam válvulas de escape para romper com algumas incertezas, provocar mudanças de comportamento, atitudes, formas de pensar, fazer, agir, imaginar e outras situações que exigem questionamentos.

Para Morin (2013, p. 24-25), "se preparar para esse mundo incerto não significa resignar-se. É preciso, pelo contrário, empenhar-se em bem pensar, elaborar estratégias, fazer apostas em plena consciência. Bem pensar significa tratar de contextualizar, globalizar nossos conhecimentos" e estar aberto ao incerto, inesperado; sensível aos acontecimentos que nos surpreende a repensar o estado das coisas, mundo e novos paradigmas em busca constante dos "fundamentos perdidos” (MORIN, 1988), uma somatória de saberes que põe em movimento, sentimentos, vida, ideias, conceitos e uma reforma do pensamento que "requer um questionamento radical que desanima as pessoas" (p. 185), mas necessária à transformação e para sair da cegueira profunda.

$\mathrm{Na}$ educação, as soluções que a escola propõe por meio de estruturas paliativas, apenas como compensação, não funcionam. Para tornar a escola um espaço de transformação e emancipação do sujeito social, é preciso romper com a política de exclusão, práticas colonialistas, transformar a relação com o saber e 
buscar uma emancipação individual e coletiva, capaz de contextualizar e globalizar. A noção de sujeito "é uma noção extremamente controvertida. Desde o princípio manifesta-se de forma paradoxal: é, simultaneamente, evidente e não-evidente" (MORIN, 1996, p. 45). Sujeito é um ser que se ocupa de signos. Trata-se de ver que talvez estejamos no fim de um certo tempo e a escola está em crise. Para sair dessa crise em que se encontra, deve permitir a relação entre a construção dos saberes e o acesso à cidadania, a relação social com o saber e a escola, a relação entre cultura e civilização (MÉDIONI, 2002), reconhecimento de identidades múltiplas, respeito à diversidade e diferença.

A educação é, desde sempre, objeto de uma diversidade de discursos emanados de pesquisadores sobre educação e escola e, muitos deles, com atenção para as representações sociais (MOSCOVICI, 1978, MORIN, 2011) e suas relações com imagens. As imagens podem alimentar as representações e estas podem definir o imaginário (CASTORIADIS, 2000) do professor, tendo contribuições da epistemologia da complexidade e seu entrelaçamento com o imaginário como "uma força atuante e pregnante da vida" (MORIN, 1988), um conhecimento multidimensional, interrogativo e "uma ética de resistência contra o fato consumado e mais abrangentemente contra barbáries de nosso tempo" (MORIN, 2000c, p. 195).

No contexto das reformas das políticas públicas educacionais para formação de professor, a educação em direitos humanos, formação do sujeito social, dignidade humana, cidadania, emancipação, são categorias pertinentes neste processo. A etno/autoformação continuada do professor é vista como um caminho cruzado ao seu desenvolvimento pessoal e profissional, inclusive porque realidades cotidianas da subjetividade, desigualdades sociais, estado de insegurança, sofrimento, falta de afetividade, discriminação e exclusão (de gênero, raça/etnia e escolarização) são desafios que o professor deve estar preparado para enfrentar na escola. A política de formação deste profissional deve favorecer integração teoria-prática, sua história de vida, experiências e vivências na escola.

\section{EPISTEMOLOGIA DA COMPLEXIDADE, REPRESENTAÇÕES E IMAGINÁRIO SOCIAL}

Os processos de implementação de políticas públicas educacionais no Brasil, sempre questionados por pesquisadores de diferentes áreas do saber e setores da sociedade civil, inclusive a formação do professor, saberes e práticas docentes, merecem mais atenção e uma forma de pensar de modo complexo. 
Na década de 90, no governo Fernando Henrique Cardoso, a formação docente foi motivo de atenção dos órgãos governamentais com a publicação de diretrizes curriculares e, no governo Lula e Dilma Rousseff, na gestão do ministro da Educação Fernando Haddad, a política de formação do professor teve como foco o preparo docente para trabalhar com temáticas atuais, inseridas no Plano de Desenvolvimento da Educação - PDE, publicado em 24 de abril de 2007.

O objetivo da política nacional de educação deve se harmonizar com os objetivos fundamentais da própria República, fixados pela Constituição Federal de 1988: construir uma sociedade livre, justa e solidária; garantir o desenvolvimento nacional; erradicar a pobreza e a marginalização e reduzir as desigualdades sociais e regionais e promover o bem de todos, sem preconceitos de origem, raça, sexo, cor, idade e quaisquer outras formas de discriminação. Não há como construir uma sociedade livre, justa e solidária sem educação republicana, pautada pela construção da autonomia, pela inclusão e pelo respeito à diversidade (BRASIL, 2007, p. 5-6).

A formação do professor, condições de trabalho, avaliação do desempenho contempladas no Capítulo I, Art. $2^{\circ}$ deste PDE institui programa próprio ou em regime de colaboração à formação inicial e continuada de profissionais da educação, a formação em serviço. Eis a questão: O que a escola e o professor de fato precisam aprender e ensinar? Que mudanças devem ser provocadas para transformar a educação, permitir a formação à cidadania? A educação transformadora e emancipatória possibilita o uso de ferramentas para romper com concepções, crenças, mitos e não permite preconceitos, impedimentos de direitos humanos, disjunção e fragmentação de saberes.

Para Kuhn (2003), uma situação de crise é entendida como imprescindível ao conhecimento, mudanças de paradigmas. Paradigma, um padrão a ser seguido; suas crenças, valores, constelação e soluções reais de quebra-cabeças são influenciados por fatores políticos, sociais, históricos e econômicos vigentes. Morin (1991a) tece críticas à imprecisão e noção khuniana de paradigma e diz que a questão não é apenas insuficiência no pensamento, mas também dificuldade de pensar a noção de paradigma que não sabemos nem isolar verdadeiramente, nem conectar verdadeiramente com a linguagem, lógica, espírito humano, cultura etc. O termo 'paradigma' khuniano apresenta

um sentido simultaneamente forte e difuso. Forte porque o paradigma tem valor radical de orientação metodológica, de esquemas fundamentais de pensamento, de pressupostos ou de crenças que desempenham um papel chave, e transporta consigo um poder dominador sobre as teorias. Difuso porque oscila entre diversos sentidos, cobrindo in extremis, de maneira vaga, a adesão colectiva dos cientistas a uma visão de mundo (1991a, p. 187). 
No pensamento dissimulado (paradigmatologia), Morin (1991a) diz que o paradigma se situa no núcleo das teorias e formula uma provocação: Mas que quer dizer paradigma? Para o autor, o sentido do termo paradigma em Platão, oscila em torno de exemplificação do modelo ou de regra e, para Aristóteles, é "o argumento que, baseado num exemplo, se destina a ser generalizado" (p. 186). Apresenta diferentes noções do termo e exemplifica a noção de facto aparentada de episteme no pensamento foucaultiano, o que define condições de possibilidades de um saber. Entende que a episteme de Foucault tem um sentido mais radical e amplo que o paradigma de Kuhn (2003), visto que se encontra quase no fundamento do saber e abarca o campo cognitivo de uma cultura, uma arqueologia do saber.

Para Foucault (2008, p. 214), a análise das formações discursivas, das positividades e do saber, "em suas relações com figuras epistemológicas e ciências, é o que se chamou, para distingui-las das outras formas possíveis de história das ciências, a análise da episteme", suspeitada,

como uma visão do mundo, uma fatia de história comum a todos os conhecimentos e imporia a cada um as mesmas normas e os mesmos postulados, um estágio geral da razão, uma certa estrutura de pensamento a que não saberiam escapar os homens de uma época - grande legislação escrita, definitivamente, por mão anônima. Por episteme entende-se, na verdade, o conjunto das relações que podem unir, em uma dada época, as práticas discursivas que dão lugar a figuras epistemológicas, a ciências, eventualmente a sistemas formalizados; o modo segundo o qual, em cada uma dessas formações discursivas, se situam e se realizam as passagens à epistemologização, à cientificidade, à formalização; a repartição desses limiares que podem coincidir, ser subordinados uns aos outros, ou estar defasados no tempo (2008, p. 214).

$\mathrm{Na}$ epistemologia da complexidade, um paradigma não pode ser atacado, contestado, vencido diretamente. Os sistemas de ideias são radicalmente organizados em virtude dos paradigmas, que exibem caráter ao mesmo tempo "semântico, lógico e ideo-lógico" (MORIN, 1991a). Propõe a definição que permite aos indivíduos conhecer, pensar, agir, segundo paradigmas inscritos culturalmente neles.

Um paradigma contém, para todos os discursos que se efectuam sob o seu domínio, os conceitos fundamentais ou as categorias mestras da inteligibilidade, ao mesmo tempo que o tipo de relações lógicas de atracção/repulsão (conjunção, disjunção, implicação ou outras) entre estes conceitos ou categorias (1991a, p. 188). 
A partir dessa compreensão de paradigma, podemos pensar que a nossa forma de ver, olhar, interpretar as coisas que vemos no mundo, produzir conhecimento de forma extremamente especializada, fragmentada de conhecer as coisas, é bastante problemática, divide, compartimenta o conhecimento e dificulta a produção de novos saberes.

A escola, instituição que faz parte da história de muitas pessoas, mas que ainda não foi alcançada por grande parte da população brasileira, está ausente de muitas vidas. As que alcançaram o acesso não conseguem permanecer em seus espaços, onde o fracasso, preconceitos, frustação, levam essa parte à evasão, abandono, exclusão social. Outros que, nela, permanecem, vivenciam medo, autoritarismo, discriminação, violências, que estão por toda parte e, muitas vezes, produzidas pela própria escola e nas dinâmicas de práticas pedagógicas verticalizadas, obsoletas, sem vida, duras para muitos que vivem o descaso, a prepotência e o abandono social pela exclusão de direitos.

O problema maior de tudo isso é que "a missão do ensino é transmitir não o mero saber, mas uma cultura que permita compreender nossa condição e nos ajude a viver, e que favoreça, ao mesmo tempo, um modo de pensar aberto e livre" (MORIN, 2001a, p. 11). A missão da escola é educar, cuidar, ensinar e aprender novos saberes e não pode se dar senão pela pesquisa, pela busca de novo espírito científico, uma realização aproximada. Conhecer é "descrever para reconhecer" (BACHELARD, 2004, p. 13). Esta formulação de Morin e Bachelard, nos convence cada vez mais a acreditar na importância de provocar uma reforma do pensamento e do ensino, criar novas estratégias para colocar novos desafios à relação cultura, escola e subjetividades.

No caso da educação, os impactos e obstáculos impostos às relações de interações presenciais e vivências de trocas de saberes são muitas vezes questionados, exige ensino remoto, requer domínio das tecnologias digitais. De fato, a escola precisa dispor de meios para conhecer o mundo, sobretudo do ponto de vista informativo, mas agora, não apenas para isso, a válvula de escape é desenvolver educação, orientada por comitês emergenciais e tecnologias digitais. Tal exigência se esbarra em desafios do uso das tecnologias pelas escolas e encontram muralhas que não permitem que interações se efetivem plenamente e muitas ações mediadas por novas tecnologias se esbarram nas limitações no uso destas ferramentas pelos professores e alunos. Diante de dificuldades de acesso à internet, exclusões digitais, há um abismo profundo entre ricos e pobres e traz provocações para se repensar a crise na educação, escola, formação do professor, quando novas desigualdades se revelam sob diferentes aspectos. 
A escola, instituição destinada a educar, ensinar, provocar socialização, interação entre as pessoas, construir conhecimentos, saberes múltiplos, convive, cotidianamente, com incertezas, insegurança, medo, violências, nos seus ambientes de aprendizagens, sociabilidades. Os diferentes atos de violência presentes na escola e ao seu entorno são frequentes e, nos últimos anos, a sua diversidade e complexidade chamam atenção de pesquisadores, causa espanto e provoca indignação sobre escolarização de qualidade, que se encontra longe de ser alcançada. Para Candau (2002), a verdade é essa: somos conscientes que reinventar a escola não é tarefa muito fácil, envolve muitas questões, representações de professores sobre práticas sociais, pedagógicas, relações de interação carregadas de preconceitos de gênero, raça/etnia etc.

Representações Sociais designa "tanto um conjunto de fenômenos quanto o conceito que os engloba e a teoria construída para explicá-los, identificando um vasto campo de estudos psicossociológicos" (SÁ, 1995, p. 19). A Teoria das Representações, idealizada por Moscovici (1978), na França, na década de 60, marcada por mudanças provocadas por conflitos e insatisfação acerca a questão que envolve as dicotomias sujeito/objeto e indivíduo/sociedade. Assim, surge com objetivo de superar o modelo científico que prioriza saberes científicos em detrimento da cultura do senso comum, não valoriza e desprestigia crenças, etnoconhecimento, conceitos culturalmente construídos na relação dialógica e cotidiana, que produz e são produzidos na cultura.

Morin (1988) levanta provocações sobre as primeiras formas de representação e uso das imagens nos ritos preparatórios de caça, aventuras, produções próprias do espírito do homem primitivo. No seu pensamento, a decoração, adorno, escultura, pintura, nas sociedades arcaicas, podem ter valor de proteção, sorte; encontram-se ligadas a crenças mitológicas e a operações rituais. Arte quer dizer destreza, habilidade, precisão, invenção no saber-fazer, atividades práticas que os homens primitivos já desenvolviam e, para compreender essa magia, é preciso retomar o duplo -, tema que emergiu a propósito da morte.

(...) a imagem não é só uma simples imagem, mas contém a presença do "duplo" do ser representado e permite, por seu intermédio, agir sobre esse ser; é esta acção que é propriamente mágica: rito de evocação pela imagem, rito de invocação à imagem, rito de possessão sobre a imagem (enfeitiçamento) (1988, p. 98-99).

Morin (2001a) diz que é a partir daí que se pode compreender a ligação entre imagem, imaginário, magia e rito. Representar significa repensar a reforma e reformar o pensamento e não se pode reformar a instituição sem anteriormente ter reformado os espíritos e não se pode reformar o espírito sem reformar as instituições. A reforma do ensino deve levar à reforma do pensamento e 
a reforma do pensamento deve levar à reforma do ensino. A educação "deve favorecer a aptidão natural da mente para colocar e resolver os problemas e, correlativamente, estimular o pleno emprego da inteligência geral" (p. 22). É da psicologia do conhecimento e da permanente aplicação dessa psicologia em si mesmo que se passa à epistemologia e ao conhecimento crítico do conhecimento para chegar às ciências cognitivas, ainda que tão mal interligadas. Há, portanto, uma aproximação entre Moscovici e Morin, quando pode-se compreender que uma cabeça-bem-feita é a que está apta a organizar conhecimentos e evitar acumulação estéril, fragmentada de saberes. Morin estabelece crítica ao marxismo, aproxima-se das ideias da multidimensionalidade do real e busca entrelaçar conhecimento pertinente e imaginário, justificando a necessidade de abandonar a falsa racionalidade. Para Morin (1993) necessidades humanas não são somente econômicas, técnicas, mas também afetivas e mitológicas.

Todo conhecimento constitui, ao mesmo tempo, uma tradução e uma reconstrução, a partir de sinais, signos, símbolos, sob a forma de representações, ideias, teorias, discursos. A organização dos conhecimentos é realizada em função de princípios e regras (...); comporta operações de ligação (conjunção, inclusão, implicação) e de separação (diferenciação, oposição, seleção, exclusão). O processo é circular, passando da separação à ligação, da ligação à separação, e, além disso, da análise à síntese, da síntese à análise. Ou seja: o conhecimento comporta, ao mesmo tempo, separação e ligação, análise e síntese (MORIN, 2001a, p. 24).

O imaginário social de professores acerca das questões educacionais e presentes na escola, suas representações sobre práticas docentes e referentes à sua profissão, sentidos e significados produzidos pelas suas narrativas do vivido, é um processo em movimento e possibilita a este profissional, desaprender e aprender em movimento contínuo.

As mudanças estão acontecendo a cada dia e isso muda nossa relação com o outro, porque o "outro" não é somente o desconhecido, o estranho, "ele é também, quem pode sofrer como nós, pode chorar como nós. O conhecido do vizinho, da pessoa com a qual se vive e o conhecimento do estranho são coisas ligadas entre si” (MORIN, 2003b, p. 36). Há uma conjunção entre o uno e o múltiplo. Deve-se chegar à inteligência cega, ela "destrói os conjuntos e as totalidades, isola todos os seus objetos do meio ambiente e não pode conceber o elo inseparável entre o observador e a coisa observada. As realidades-chave são desintegradas" (MORIN, 2011, p. 12). Em "Meus Demônios", o autor (2000c) diz diretamente que a antropologia se torna mais complexa, e depois novos elementos foram desenvolvidos em "Paradigma Perdido".

Com L'Homme et la Mort, e em seguida, Le Cinéma ou lHomme imaginaire, o 
mito e o imaginário ocuparam um lugar radical em minha antropologia: não são superestruturas, vapores; a realidade humana é semi-imaginária nela mesma. E reconheço o lugar do mito e do imaginário em nossa sociedade com Les Stars e L'Esptrit du temps (MORIN, 1988, p. 196).

Morin promove esse diálogo há décadas, mas suas reflexões permanecem vivas sobre o princípio de incerteza política, quando é possível ainda perceber que este princípio "não nos diz que não poderemos melhorar as relações entre os homens, nem que a humanidade não conseguirá civilizar a terra" (2000c, p. 250). Um enigma, uma visão mágica do mundo e o pensamento são não se propõe a decifrar o enigma, ele traz consigo a consciência do enigma. "O real é mitômano, como a magia. Seus mitos fundamentam-se ao mesmo tempo na atividade prática do homem e nas regularidades estruturadas do mundo exterior: são o objeto, a ação" (MORIN, 2003ª , p. 35). Assim, o autor deixa a porta aberta à esperança, propõe que o diálogo entre a experiência e a desesperança precisam ser promovidos para se chegar ao ponto "X" da questão - um sujeito à flor da pele.

O sentimento da realidade é o produto de um fluxo afetivo constante, e esse fluxo (...) pode até mesmo ser suscitado pelo imaginário; será que sempre existe algo de imaginário na noção-sentimento de realidade? A fórmula 'realidade semiimaginária do homem' pretende indicar que se o imaginário é semi-real, o real é semi-imaginário... (2003a, p. 35).

A escola ainda continua, por um lado, a privilegiar apenas um lado da moeda, o imaginário social dominante, autoritário, preconceitos, crenças, mitos permanecem mais fortes do que as sociabilidades, cidadania. Tensões e conflitos na relação ensino-investigação e interação teoria-prática por parte do professor e suas práticas docentes são questionados há muitos anos, e formas de controle do conhecimento têm sido enquadradas como problemáticas à qualidade do sistema educativo (GATTI, 2019).

Por outro, a escola não se importa com a implementação de políticas públicas em seus espaços socioeducativos e seus professores não se encontram preparados para enfrentar os problemas e aplicar conhecimentos novos, que a todo vapor surgem na sociedade contemporânea. A questão é desconcertante: a acessibilidade da escola inclusiva acerca das tecnologias, recursos pedagógicos e atendimento educacional multidimensional são ainda insuficientes. Precisa acreditar no caráter dinâmico do saber científico, atentar-se para a relação inevitável entre objetividade e subjetividade e, para configurar-se como sujeito, "conhecerse e transformar-se. O ser humano precisa de um objeto, e, nessa relação sujeito e objeto emergem na realidade complexa, o que também se observa entre sistema auto-organizador e ecossistema" (PETRAGLIA, 2001, p. 38). Mas também, 
podemos encontrar professores que têm se preocupado com mudanças de suas práticas e atuação pedagógica, que buscam uma visão renovadora de educação e formação de seus alunos, privilegiam conhecimentos inter/transdisciplinares, multidimensionais, articulando teoria-prática, ensino, pesquisa e intervenções pedagógicas e ficam cada vez mais longe de práticas autoritárias, reprodutoras de conhecimentos especializados.

O professor é um ator muito importante na qualidade do ensino e nas relações de interações na escola, ele é o enfoque principal quando se pretende estudar o contexto escolar. É impossível "desconhecer que sem professor não se faz escola e, consequentemente, é fundamental aprofundar estudos sobre ele" (CUNHA, 1989, p. 27). A vida de professor, suas experiencias no cotidiano escolar, sempre foram motivos de provocações e pesquisas, então, é essencial saber quem são os bons professores. Como definir quem são eles? Suas histórias de vida, vivências, dificuldades, potencialidades, indagações? Gostos, desejos, planos de vida, oportunidades de se perceber bom ou mau professor, significações imaginárias, capacidade de criação, significados e sentidos criados acerca da docência, do ser professor, a produção de narrativas do vivido, suas representações.

Ferreira e Eizirik (1994) tratam da educação e imaginário com a intenção de rever a escola. Observam que

São inúmeras as reflexões acerca da educação em geral e da escola em particular. Cientistas de diferentes áreas do conhecimento vêm aceitando o desafio de reconsiderar seus saberes e fazeres no avanço das ciências. Há como um consenso de que não existe uma metalinguagem geral, única, sob a qual todas as produções científicas devam ser traduzidas, transcritas e avaliadas. Após tantos anos de cientificismo, parece ter chegado a momento da desconfiança, das incertezas, das dúvidas diante de verdades instituídas. Saberes inquestionáveis, frutos de investigações empíricas elaboradas com bastante rigor, apontam agora para suas zonas sombrias. Descobre-se que o real e o ideal, o concreto e o abstrato, a matéria e as relações são conceitos instituídos socialmente e que neles está presente o modo de produção de seus sentidos. Olhares diversos constituem seus objetos de conhecimento, e cada cientista sabe que seu olhar é apenas um dos possíveis olhares. Isto quer dizer que a complexidade está sempre presente na produção do conhecimento. Essa complexidade significa a possibilidade que um objeto ou um sujeito têm de comportar muitos elementos, múltiplas interações (1994, p. 4).

Vistos dessa forma, questionar como a ciência é produzida, socializada, divulgada, é muito importante para compreender conflitos e complexidades de uma sociedade, grupo social. Uma observação pode ser feita aqui. $\mathrm{O}$ imaginário social e projeto colonialista autoritário, primeiro resultado do encontro de colonizadores portugueses com indígenas e, posteriormente, com a chegada dos africanos, aqui 
escravizados, além de asiáticos, promoveram encontros e desencontros entre eles, na formação da sociedade brasileira e as ideologias, crenças e mitos, frutos das zonas de contato persistem.

A complexidade é cada vez uma cumplicidade de desconstrução, arquitetura, uma noção mais lógica do que quantitativa, é criação, transformação do todo sobre as partes e das partes sobre o todo. Há influência do todo sobre as partes e das partes sobre o todo, eles são interligados (MORIN, 2000a, 2001b). Infelizmente, o progresso científico e benefícios da tecnologia ainda não foram alcançados por todos, apenas uma pequena minoria tem acesso suficiente a esses serviços e outra parte ainda não alcançou e vivencia dificuldades de acompanhar avanços sociais por estes mecanismos de interações sociais e virtuais. Morin "é um pensador hologramático, dialógico, "da complexidade, imaginário, compreensão e de uma sociologia do cotidiano e do presente" (SILVA, 2002, p. 14), observador da vida, experimenta, faz e "ultrapassa os limites da metodologia para configurar uma teoria e um imaginário do conhecimento" (p. 18). A ciência com consciência é uma realidade mutilada e mutiladora e, ainda nas palavras de Clotet (2002, p. 11),

O progresso científico, os avanços da genética molecular e a experimentação embrionária humana não podem ser realizados à toa. $\mathrm{Na}$ medida do possível, a sociedade como um todo, o que infelizmente constitui uma aspiração ainda irrealizável em nosso país, assim como em muitos outros, deveria intervir no uso e na prática conscienciosa ou eticamente adequada dos resultados das novas tecnologias em benefício da vida planetária e particularmente da vida humana.

Para Schnitman (1996), a sociologia do conhecimento, ciências cognitivas, modelos co-construtivistas e construcionistas em psicologia e educação são importantes ao diálogo aberto entre a ciência, cultura e subjetividade, para adquirir formas de compreender e participar, metáforas e parâmetros, eixos cognitivos e destrezas específicas. Essa compreensão encontra eco naqueles (BRUNER, 1986, 1990; MOSCOVICI, 1978; MORIN, 1991b) que se dedicam ao novo conhecimento, imaginário social, concepção de cultura e desenvolvimento humano.

$\mathrm{Na}$ teoria das representações sociais, a ruptura das correntes que a subjetividade e relações se organizam no traçado de metáforas e horizontes, "geram pressupostos e expectativas, configurando-se crenças, epistemologias cotidianas e visões de futuro (SCHNITMAN, 1996, p. 10). O problema é que a escola, apesar de viver e atravessar mudanças de paradigmas, não consegue ainda olhar o tripé ciência, cultura e subjetividade sob uma ótica multidimensional, transformativa, e suas respostas às questões da contemporaneidade são insuficientes. 
A recomendação de refazer o caminho do conhecimento científico e a educação, incluindo o ensino das incertezas, "ensinar princípios de estratégia que possa permitir enfrentar imprevistos, o inesperado, a incerteza e modificar seu desenvolvimento em virtude das informações adquiridas ao longo do tempo" (MORIN, 2000a, p.16) é possível. Desde que a escola e suas representações hegemônicas sobre resistência e incompreensão de seu estado bárbaro, decorrentes das raízes formadoras da sociedade e dela própria, deixem de operar, dando lugar a possibilidades de mudanças de práticas pedagógicas e docentes. As mudanças não ocorrerão sem a escola aprender a "navegar em um oceano de incertezas em meio a arquipélagos de certezas" (2000a, p. 16).

Nessa perspectiva, considerações éticas e estéticas do ser humano e de seus contextos sociais são urgentes, num momento em que crises na educação se acirram e faces da sociedade com ameaças ao Estado democrático de direito se escancaram por discursos recheados de arrogância, personalidades totalitárias, negacionismos de evidências incontestáveis, ameaças fascistas-nazistas que tomam as ruas, aceleração de desigualdades sociais. A sociedade, tal como estamos vivendo, é caótica, mas cheia de causas e efeitos, e abre espaços para nova forma de pensar e (re)pensar a forma de viver, de novos diálogos, compartilhamentos de conhecimentos e interpretações do mundo.

A ciência, os processos construtores de e construídos por processos sociais marcados pelas relações de gênero, raça/etnia, classe social etc, exigem competência, criatividade, domínio de habilidades, uma ética da compreensão (MORIN, 1996). O paradigma da complexidade à elaboração do conhecimento considera um novo método para religação dos saberes e recusa simplificações abstratas.

O problema da complexidade tornou-se uma exigência social e política vital do nosso século: damo-nos conta de que o pensamento mutilante, isto é, o pensamento que se engana, não porque não tem informação suficiente, mas porque não é capaz de ordenar as informações e os saberes, é um pensamento que conduz a acções mutilantes (MORIN, 1991b, p. 14).

Por fim, esta é uma discussão inesgotável, mas podemos encerrar neste ponto de vista, com base na provocação de que a crise de confiança na ciência abre lacunas e provocam outras crises que atingem diferentes sociedades humanas. Portanto, é preciso buscar transformar o pensamento, a escola e a educação. 


\section{CRISES NA EDUCAÇÃO, ESCOLA E FORMAÇÃO DE PROFESSOR}

A crise na educação, escola e formação docente vem passando por inúmeras dificuldades com a produção do conhecimento, cidadania, democratização de processos pedagógicos, gestão, modos de pensar docente e resistências às mudanças de perspectivas para enfrentar novos desafios contemporâneos.

A vida vulnerável em tempos sombrios coloca a escola a enfrentar novos atos de violência, autoritarismo, ambiguidades, descompassos, ambivalências, problemas que cercam suas concepções de ensinar-aprender e disjunção teoriaprática. Como ficam os que "habitam a cidade sem ter direito à cidade, já que, vivendo em espaços desurbanizados, não têm acesso às condições urbanas pressupostas pelo direito à cidade" (SANTOS, 2020, p. 18). Condições de aprendizagem e crises na educação são motivos de preocupação. Como pensar na educação humana, diante de situações que tendem a tirar a dignidade do ser humano? A sociedade vive uma situação democrática que carece de capacidade política para responder diversas emergências. Santos (2020) chama atenção às democracias que estão cada vez mais vulneráveis às fake nenws, desigualdades de oportunidades, negação de direito a ter direitos e recomenda que temos de imaginar soluções democráticas assentes na democracia participativa ao nível dos bairros, comunidades, orientada à solidariedade, cooperação, e não ao empreendedorismo e competitividade a todo custo.

Em momentos difíceis, com a desautorização da ciência, obscuridade, onde tudo se torna confuso, o esfacelamento da escola e da educação, aumento da pobreza, desigualdades sociais se arrastam ao abismo de forma desastrosa e assustam. Somos capazes de compreender, cada vez mais, sobre a importância e coerência de todas as coisas, inclusive estamos mais convencidos "da necessidade de uma reforma do pensamento, portanto de uma reforma no ensino" (MORIN, 2001a, p. 9). Deve-se aproveitar diversas oportunidades para refletir sobre o assunto, a ciência, escola, educação, que se pretende democrática, dialógica, participativa e valorizar a reforma do pensamento. É através da educação que podemos buscar novas formas de viver novas sociabilidades, relacionamentos, mas as dificuldades são plurais, inclusive porque nos encontramos presos a um imaginário que determina nossa forma de interagir afetivamente e em relação ao pensamento. Por isso, desde cedo é preciso estimular a criança a pensar, ao exercício da ética da compreensão, na família, escola, nos quais ela convive com outras crianças e adultos, e criar alternativas para burlar com as existentes imagens dominantes do pensamento, na vida e formas de construções do mundo em que vive. As imagens monopolizam o seu imaginário, condicionam sua maneira de 
agir, pensar, narrar, sentir e de se relacionar afetivamente com as outras crianças e adultos ao seu redor. Esse imaginário dominante de que falamos aqui nos leva a Castoriadis:

O imaginário de que falo não é imagem de. É criação incessante e essencialmente indeterminada (social-histórica e psíquica) de figuras/formas/imagens, a partir das quais somente é possível falar-se de "alguma coisa". Aquilo que denominados "realidade" e 'racionalidade" são seus produtos (2000, p. 13).

Para Durand (2002), o campo do imaginário é formado pela atuação do símbolo e da imaginação que agem juntos e, para Coelho (1999, p. 212),

O conjunto das imagens não gratuitas e das relações de imagens que constituem o capital inconsciente e pensado do ser humano. Este capital é formado pelo domínio do arquetipal - ou das invariâncias e universais do comportamento do gênero humano - e pelo domínio do ideográfico, ou das variações e modulações do comportamento do homem localizado em contextos específicos e no interior de unidades grupais. Não se trata, portanto, de um conjunto de fantasias no sentido de irrealidades mas de um substrato simbólico ou conjunto psicocultural (...) de ampla natureza, que se manifesta formas.

É difícil imaginar quando a ignorância se instala de tal modo como forma exagerada de ódio e alergia ao aprender, uma "epistemofobia" à aprendizagem e, hoje, parte da população vive a explosão da ignorância acerca da tecnologia e informação. Em Bunge (2002), ignorância é falta de conhecimento. A ação científica "é, por excelência complexa; é do lado das verdades fictícias e complexas e não do lado das verdades adventícias e claras que se desenvolve o empirismo ativo da ciência" (BACHELARD, 2000, p. 147); formar a razão da mesma maneira que é preciso formar a experiência. O enigma é saber os porquês da não efetivação desse pensamento e objetivos na escola, e por que ainda não oferece um conjunto de saberes capaz de unir, reajuntar o pensamento, razão, emoção, permitir e ensinar a condição humana e suas dimensões cósmicas, terrestres, metafísicas, físicas, humanas. Por que permite a continuação, produção/ reprodução de confortos disciplinares, descontextualizados, saberes fragmentados, representações da disciplinarização. A crença e elogios extremos à especialização produzem fragmentação, separa conhecimentos, dificulta o diálogo entre áreas do saber. A ausência de diálogo entre construtores do saber leva a ignorância. Para Morin (2002), o problema da ignorância especificada impede tudo que procuramos detalhar, especificar, analisar, estudar, investigar. A especificação que é, inevitavelmente, incompleta denuncia que o item a ser investigado é em grande parte ignorado. 
Para Bunge (2002, p. 184),

Um pré-requisito da pesquisa em qualquer campo é o interessado admitir que ignora algo digno de ser conhecido. Para que tal admissão e avaliação sejam férteis elas devem ser específicas e não genéricas: devem descrever, tão precisamente quanto possível, o que é isto que não conhecemos e que devemos investigar (...).

Morin (2001a) trata dos desafios que precisamos enfrentar para repensar a reforma e reformar o pensamento e observa inadequação cada vez mais ampla, profunda, grave entre saberes fragmentados, separados, dissociados, compartimentados entre disciplinas. Não se comunicam, não há diálogo entre os saberes, uma atitude que rejeita o conhecimento complexo, transdisciplinar e a responsabilidade por um sistema de ensino e educativo que possibilite a saída de uma idade de ferro planetária, da pré-história do espírito humano e volta a atenção ao campo da hiperespecialização dos saberes, "impede de ver o global (que ela fragmenta em parcelas), bem como o essencial (que ela dilui)" (p. 13). Por outro, estão as realidades ou problemas cada vez mais polidisciplinares, transversais, multidimensionais, transnacionais, globais, planetários e há outros desafios que se referem a possibilidade de se "opor um futuro radioso a um passado de servidões e superstições. Todas as culturas têm suas virtudes, experiências, sabedorias, ao mesmo tempo que suas carências e ignorâncias" (MORIN, 2002, p. 124).

A escola sempre esteve presente na vida da humanidade e ocupa lugar importante nas sociedades, mas questionamentos sobre o futuro da educação são diversos. A desigualdade social mostra que é perversa com negros, pobres, moradores de periferias, desempregados. Portanto, é preciso encontrar caminhos possíveis para enfrentar crises na educação e a escola buscar mudanças para transformar esse cenário educacional e humano.

\section{CONSIDERAÇÕES FINAIS}

Em tempos sombrios, de autoritarismo desenfreado, escancarado, crises na educação e pandemia de COVID 19, que impõem muitas dificuldades e desafios a serem enfrentados pela escola e sociedade brasileira, é preciso tentar escapar da insegurança, medo e incertezas, tendo que, certamente, reinventar o tripé educação, escola e professor.

É preciso modificar as relações humanas para enfrentar novos desafios que foram colocados e têm mostrado que há inúmeras possibilidades de luta, resistência, superação. Apresentar estratégias para percorrer caminhos, buscar formas de encontros, inovações nos modos de relacionamento com as pessoas e ambiente em que vivemos. $\mathrm{Na}$ escola, esperamos que ela seja de qualidade e 
para todos, acolha a diversidade, um lugar de diálogos pertinentes, espaço de sociabilidades, construção de novos conhecimentos. O professor, para atender às exigências da sociedade, deve estar preparado para ensinar-educar para os novos tempos.

Para isso, é pertinente que este profissional participe de cursos, debates, reflexões, que lhes proporcione educação continuada, ética da compreensão, conhecimentos de temáticas atuais, conteúdos integrados, interrelacionados, que facilitem as vias da compreensão, recorrendo a vias intelectuais, éticas, na perspectiva de desenvolvimento da dupla compreensão, intelectual e humana (MORIN, 2000b, 2000d).

Para alcançar estes objetivos e a qualificação profissional do professor, é muito importante aplicar e implementar políticas públicas e sociais que exigem atenção das instituições e ações governamentais, educar pela integração ensino, pesquisa, intervenção e elaborar um projeto contra o "fracasso", organizar princípios e processos de propostas pedagógicas emancipatórias, inovadoras, enfrentar crises geradas pela opressão, autoritarismo, ignorância.

Tudo isto nos deixa insatisfeitos: de um lado, a escola não se importa de buscar mudanças de processos pedagógicos, acompanhar avanços sociais, estimular a formação continuada do professor e nem o aluno ao desejo de conhecer, dialogar, formular a incansável busca pelas respostas aos seus questionamentos, dúvidas. Continua a manter saberes pedagógicos, métodos, técnicas e procedimentos de forma autoritária, burocrática. Enfim, a maneira como a escola se impõe à construção do conhecimento e a formação do sujeito nos seus espaços pedagógicos não desperta a criatividade e o pensamento. O acesso é dificultado pelas desigualdades sociais, condições de moradia. A educação e o ensino público escolar estão em jogo, assim como o sentido da escola e sua relação com o saber. É preciso encontrar o sentido da escola, refletir sobre tudo, imaginar, inventar, elaborar hipóteses, criticar quando as coisas não estão dando certo, estimular o pensamento, a reflexão, o diálogo. Enfim, acreditamos que a escola pode e deve ser um espaço de produção de sentidos, vida, trocas, enriquecimento de saberes, sociabilidades e representações. 


\section{REFERENCIAS}

BACHELARD, Gaston. Ensaio sobre o conhecimento aproximado. Tradução Estela dos S. Abreu. Rio de Janeiro: Contraponto, 2004.

BACHELARD, Gaston. O novo espírito científico. Tradução Juvenal H. Júnior. Rio de Janeiro: Tempo Brasileiro, 2000.

BUNGE, Mario. Dicionário de Filosofia. Tradução Gita K. Guinsburg. São Paulo: Perspectiva, 2002.

CANDAU, Vera Maria (Org.). Reinventar a escola. Petrópolis: Vozes, 2002.

CASTORIADIS, Cornelius. A instituição imaginária da sociedade. Tradução Guy Reynaud. Rio de Janeiro: Paz e Terra, 2000.

COELHO, Teixeira. Dicionário crítico de política cultural: cultura e imaginário. São Paulo: Iluminuras/FAPESP, 1999.

CUNHA, Maria Isabel da. O bom professor e sua prática. São Paulo: Papirus, 1989.

DURAND, Gilbert. As estruturas antropológicas do imaginário. Tradução Hélder Godinho. São Paulo: Martins Fontes, 2002.

FOUCAULT, Michel. A arqueologia do saber. Tradução Luiz F. B. Neves. Rio de Janeiro: Florense Universitária, 2008.

GEERTZ, Clifford. Nova luz sobre a Antropologia. Tradução Vera Ribeiro. Rio de Janeiro: Jorge Zahar, 2001.

MORIN, Edgar; VIVERET, Patrick. Como viver em tempo de crise? Tradução Clóvis Marques. Rio de Janeiro: Bertrand Brasil, 2013.

MORIN, Edgar. Introdução ao pensamento complexo. Tradução Eliane Lisboa. Porto Alegre: Sulina, 2011.

MORIN, Edgar. X da questão: o sujeito à flor da pele. Tradução Fátima Murad e Fernanda M. Machado. Porto Alegre: Artmed, 2003a. 
MORIN, Edgar; WULF, Christoph. Planeta: a aventura desconhecida. Tradução Pedro Goergen. São Paulo: UNESP, 2003b.

MORIN, Edgar. Em busca dos fundamentos perdidos. Tradução Maria L. Rodrigues, Salma Tannus. Porto Alegre: Sulina, 2002.

MORIN, Edgar. A cabeça bem-feita: repensar a reforma, reformar o pensamento. Tradução Eloá Jacobina. Rio de Janeiro: Bertrand Brasil, 2001a.

MORIN, Edgar (Org.). A religação dos saberes: O desafio do século XXI. Tradução Flávia Nascimento. Rio de Janeiro: Bertrand Brasil, 2001b.

MORIN, Edgar. Os sete saberes necessários à educação do futuro. Tradução Catarina Eleonora F. da Silva, Jeanne Sawaya. São Paulo: Cortez; Brasília: UNESCO, 2000a.

MORIN, Edgar. Ciência com consciência. Tradução Maria D. Alexandre e Maria A. S. Dória. Rio de Janeiro: Bertrand Brasil, 2000b.

MORIN, Edgar. Meus demônios. Tradução Leneide Duarte e Clarisse Meireles. Rio de Janeiro: Bertrand Brasil, 2000c.

MORIN, Edgar; LE MOIGNE, Jean-Louis. A inteligência da complexidade. Tradução Nurimar M. Falci. São Paulo: Peirópolis, 2000d.

MORIN, Edgar. A noção de sujeito. In: SCHNITMAN, Dora Fried (Org.). Novos paradigmas, cultura e subjetividade. Tradução Jussara H. Rodrigues. Porto Alegre, RS: Artes Médicas, 1996. p. 45-58.

MORIN, Edgar et al. A decadência do futuro e a construção do presente. Florianópolis, SC: UFSC, 1993.

MORIN, Edgar. O método IV. As ideias: a sua natureza, vida, habitat e organização. Tradução Emílio C. Lima. Portugal: Europa-América, 1991a.

MORIN, Edgar. O problema epistemológico da complexidade. Portugal: Europa-América, 1991b. 
MORIN, Edgar. O paradigma perdido: a natureza humana. Tradução Hermano Neves. Lisboa: Europa-América, 1988.

PETRAGLIA, Izabel Cristina. “Olhar sobre o olhar que olha”: complexidade, holística e educação. Petrópolis: Vozes, 2001.

SCHNITMAN, Dora Fried. Introdução: Ciência, cultura e subjetividade. In: SCHNITMAN, Dora Fried (Org.). Novos paradigmas, cultura e subjetividade. Tradução Jussara H. Rodrigues. Porto Alegre, RS: Artes Médicas, 1996. p. 9-21.

\section{Maria de Fátima de Andrade Ferreira}

Pós-Doutorado em Antropologia Social pelo Programa de Pós-Graduação Multidisciplinar em Estudos Étnicos e Africanos, pelo Centro de Estudos AfroOrientais, da Faculdade de Filosofia e Ciências Humanas, da Universidade Federal da Bahia (UFBA), Doutorado em Educação pela UFBA, Professora Titular da Universidade Estadual do Sudoeste da Bahia (UESB), Programa de PósGraduação em Ensino, (PPGEN), Campus de Vitória da Conquista; Programa de Pós-Graduação Mestrado em Relações Étnicas e Contemporaneidade (PPGREC), Campus de Jequié e do curso de Pós-Graduação Lato Sensu, Especialização em Relações Étnico Culturais e Diversidade. Coordena o Núcleo de Pesquisa e Extensão Gestão em Educação e Estudos Transdisciplinares (NUGEET) e Rede de Pesquisa Representações, Discursos e Violência na Escola - olhar, pensar e agir sobre a formação de valores, atitudes e permanência do aluno na sala de aula (UESB/FAPESB).E-mail: mfatimauesb@hotmail.com

\section{Cinthia Maria Seibert Santos}

Mestre em Educação pelo Programa de Pós-Graduação em Educação e Contemporaneidade da Universidade do Estado da Bahia. Coordenadora Pedagógica da Prefeitura Municipal de Salvador. Professora do Centro Universitário Mauricio de Nassau. Colaboradora do Conselho Estadual de Educação - CEE Bahia para procedimentos de avaliação de cursos de graduação, da Rede SESI de Educação- consultora Ad hoc Seminário de Boas Práticas e da Pró-Reitoria de Extensão PROEX/UNEB em Comitês Internos de Avaliação de Projetos e Programas submetidos a editais próprios. Membro da Rede de Pesquisa Discursos, Representações e Violência na Escola, da Universidade Estadual do Sudoeste da Bahia- UESB e do Grupo de Pesquisa Formacce Infância, Linguagens e EJA- UNEB. E-mail: cinthiaseibert@yahoo.com.br 